\title{
COMPARING THE EFFECT OF SECNIDAZOLE AND METRONIDAZOLE FOR THE TREATMENT OF GIARDIASIS IN CHILDREN
}

\section{A. Modarresi}

Paediatrics, Mashhad University of Medical Science, Mashhad, Iran

Giardiasis is one of the most common intestinal parasitic infection among children. It is a world wide and an important disease in Iran.

Abdominal pain, bloat, chronic or intermitant diarrhea and steaturrhea which cause malabsorption are the main clinical signs.

The etilogic agent is Giardia lamblia which is found in the form of trophozite

(pathogenic form) and cyst (infective form).

The infective form is Transmitted by water, direct contact, vegetables and flies In order to evaluate the efficacy of secnidazole (a new drug) and comparing with the effect of metronidazole, a study was undertaken over a 15 month period on 83 patients suffering from giardiasis in Imam Reza Hospital.

After a questionair was complited for each patient, the patients were treated with secnidazole $(30 \mathrm{mg} / \mathrm{kg}$ single dose) and metronidazole (15 mg/kg tid for 7 days) randomly. Two weeks after the end of treatment, direct and formol- ether fecal examination was performed on 3 consecutive days for each child.

Examinations showed that secnidazole is effective in $94.4 \%$ and metronidazole is effective in $80 \%$ of infected children $(\mathrm{P}<0.05)$.

Since secnidazole had milder side effects and was more effective in relation to metronidazole and it can be used in single dose it can be concluded as a better drug than metronidazole for treatment of giardiasis in childrens. 